\title{
Investigation of effective parameters on brackish water desalination by flow-electrode capacitive deionization
}

\author{
Khadijeh Dehghan*, Seyed Ahmad Mirbagheri, Mahdi Alam \\ Department of Civil and Environmental Engineering, K.N. Toosi University of Technology, \\ No. 1346, Vali Asr Street, \\ Mirdamad Intersection, Tehran, Iran, Tel. +98(21)88779474; Fax +98(21)88779476; emails: \\ khdehghan@mail.kntu.ac.ir (K.Dehghan),mirbagheri@kntu.ac.ir(S.A. Mirbagheri), \\ m.alam@yazd.ac.ir (M.Alam)
}

\begin{abstract}
Population growth and increasing global demand for freshwater have raised a serious challenge for the depleting sources of freshwater in the $21^{\text {st }}$ century. Desalination technologies can be a reliable technique for providing freshwater. Capacitive deionization is one of the innovative desalination methods that has received increasing interest. Flow-electrode capacitive deionization (FCDI) (a new architecture of capacitive deionization) is one of the efficient, costeffective, and environmentally-friendly desalination methods for freshwater production. In this experimental research, the performance of an FCDI system was investigated and the influence of important parameters such as flow rate of flow-electrodes, electrolyte salt concentration of flow-electrodes, and initial feed water concentration will be assessed on the efficiency of desalination operation.
\end{abstract}

In this study, the flow-electrodes operated in short-circuited closed-cycle operation (SCC) mode, and also the feed water operated similarly to the flow-electrodes in closed-cycle. Moreover, in all the experiments, the salt adsorption capacity (SAC) and salt removal efficiency (SRE) was calculated. Herein, by optimizing the above mentioned parameters, the salt removal efficiency of $83 \%$ and a SAC value of $29.12 \mathrm{mg} / \mathrm{g}$ dry carbon were achieved in 5 hours.

Keywords: Water desalination, Flow-electrode capacitive deionization, Salt removal efficiency (SRE), Salt adsorption capacity (SAC)

\section{Introduction}

Water is a basic need for human survival and thus, access to safe and clean water is an important necessity for human societies. In recent decades, factors such as population growth, industrial and economic growth, improved standards of living, changing consumption patterns and the expansion of agriculture have increased global demand for water and thus pressure on water resources in many parts of the world. About two-thirds (4 billion people) of the world's population is affected by severe water shortages in at least one month of the year, nearly half of them in India and China. It is remarkable that half a billion people in the world suffer from severe water shortages all year round [1]. The United Nations Educational, Scientific and Cultural Organization (UNESCO) also estimates that nearly one-third of the world's population now lives in water-scarce areas, a figure that is expected to double by 2025 [2].

Water resources cover about three-quarters of the earth's surface. Nevertheless, the acute shortage of drinking water in Africa and the countries of the Middle East is extremely tangible. Only $2.5 \%$ of the earth's water resources are freshwater in groundwater, lakes, rivers, surface water, and also in the form of ice and snow in mountainous and polar areas (inaccessible), and 
much of the resources as salt water are in seas and oceans and some lakes [3], [4]. To find a solution to the problem of water scarcity, desalination of sea and brackish water can be considered as a suitable and economical option.

According to the guidelines of the World Health Organization (WHO), the permissible TDS level of potable water should be less than $500 \mathrm{ppm}$, but in certain cases, it can be as high as $1000 \mathrm{ppm}$. However, TDS concentration is reported in the range of 1000-25000 ppm for brackish water and 35000-45000 ppm for seawater [3], [4]. Therefore, the use of an efficient and effective desalination method can be very helpful and promising in reducing the urgent need for water around the world. Various factors are involved in the selection of a desalination process for the production of potable water, such as the quality of the feed water entering the desalination system, the concentration of the desalinated water (product), the amount of energy entering the system, the environmental impact (e.g., $\mathrm{CO}_{2}$ emissions and secondary pollutants), and the cost.

The most common desalination technologies in water-scarce areas around the world include thermal phase change processes, membrane processes, and chemical desalination methods. Among the most important thermal phase change processes are multi-stage flash distillation (MSF), multiple-effect distillation (MED), mechanical vapor compression distillation (MVC), humidification-dehumidification desalination (HDH), solar distillation (SD) and freezingmelting (FM). It can be stated that the most important membrane processes include reverse osmosis (RO), forward osmosis (FO), electro-dialysis (ED), membrane distillation (MD), and nanofiltration (NF). In addition, to introduce chemical desalination processes, one can mention ion-exchange desalination (I.Ex), liquid-liquid extraction (LLE), and gas hydrate (G.Hyd). Most desalination facilities in the world are based on reverse osmosis (RO) and multistage flash distillation (MSF) methods [5]. Due to the significant energy consumption involved in these technologies (RO: 2-4 $\mathrm{KWh} \mathrm{m}^{-3}$, MSF: 55-80 $\mathrm{KWh} \mathrm{m}^{-3}$ ), emerging technologies such as electrochemical desalination processes have attracted considerable attention [5]. Electrochemical desalination technologies can be introduced as an effective and promising solution for efficient energy management and the reduction of greenhouse gas emissions. An important group of electrochemical desalination processes, known as capacitive deionization process, consists of three main categories: capacitive deionization (CDI), membrane capacitive deionization (MCDI), and flow-electrode capacitive deionization (FCDI).

In the previous study, we discussed the assembly of a typical FCDI system and the removal efficiency of this system in desalination of brackish water [6]. In this paper, we now discuss the effect of important and effective parameters on the efficiency of this system for the removal of salt ions from brackish groundwater using the batch mode FCDI experiments under a closed cycle. In other words, by conducting the FCDI experiments and plotting the comparison diagram, we investigate the effect of factors such as flow-electrodes flow rate, initial sodium chloride concentration of feed water, and salt concentration of electrolyte solution of flowelectrodes on the desalination efficiency of the FCDI system.

\subsection{FCDI process definition}

CDI was first introduced by D. D. Caudle et al. (1960) [7] and proposed as an option for desalination of brackish water. 
In capacitive deionization processes, the feed water is passed through the oppositely charged electrodes. In fact, the electrodes are charged by a potential difference (less than $1.23 \mathrm{~V}$ [8][10]) under an electric field. As a result, the ions in the feed water migrate to the surface of the charged electrodes and are charged accordingly. In this process, the electrical double-layer (EDL) actually forms in the electrode/electrolyte interface. After the charged ions reach the surface of the electrodes, they are accumulated inside the EDLs by electrostatic forces and are electrostatically held [11], [12]. The performance of electrical double-layer capacitors (EDLCs) is similar to conventional capacitors. Conventional capacitors consist of a dielectric sandwiched between the two opposing electrodes, but EDLCs use a double layer for nanoscale charge separation [11]. In addition, the structure of electrodes in capacitive desalination processes is composed of nanostructured carbon materials. Among the properties that are expected of carbon materials used in the electrode structure in electrochemical desalination processes are highly extended surface area and pores matching the size of the electrolyte ions, appropriate pore distribution, excellent electrical conductivity, and good chemical stability [2], [11].

As mentioned earlier, a conventional CDI cell contains two fixed electrodes located on either side of a spacer. In fact, the space between the two electrodes is considered as a water flow path. By applying an electrical voltage to carbon electrodes, cations $\left(\mathrm{Na}^{+}\right)$and anions $\left(\mathrm{Cl}^{-}\right)$in the feed water flowing in the spacer channel, migrate to carbon electrodes (cations are adsorbed by the cathodic electrode and anions by the anodic electrode). The ions are eventually adsorbed in the EDL and consequently, $\mathrm{NaCl}$ is removed from the feed water. After ion electrosorption (adsorption), the ion-saturated electrodes should either be replaced with a set of new electrodes or regenerated. Since the fixed electrodes used in conventional CDI have a limited ion adsorption capacity, the saturated electrodes can be regenerated during the ion desorption process by short-circulating or reversing polarity. In this way, the adsorbed ions return to the brine stream and the electrodes regenerate their ion adsorption capacity [2], [13], [14]. Saturation of the electrodes with ions, so that the electrodes do not have the capacity to adsorb more ions, is the main limitation of conventional CDI technology, as it limits the desalination of feed water with very high concentrations. Therefore, researchers have tried to overcome the limitations of conventional CDI using new technologies, such as static electrode architecture (e.g., flow-through electrode CDI [15], membrane CDI [16]-[19], inverted CDI [20], hybrid CDI [21], wire based CDI [22], and desalination battery [23]), and flow-electrode architecture (e.g., feed-in electrodes [24], feed-between electrodes [25], and membrane flow-electrodes [26]) [27].

Membrane capacitive deionization (MCDI) technology is considered a significant improvement over conventional CDI. MCDI is the product of mixing conventional CDI and ion-exchange membranes (IEMs). In MCDI, the IEMs are located in front of the CDI electrodes and, in fact, between the electrodes and the spacer chamber, which increases the adsorption and desorption of ions (compared to conventional CDI) and thus increases ion removal efficiency compared to conventional CDI. In other words, IEMs can be considered as porous separators. Also, the use of membranes is an effective method of reducing certain Faradaic reactions, such as the cathodic reduction of oxygen and the anodic oxidation of carbon [12], [28]. During the 
regeneration process, the membranes limit the adsorption of co-ions ${ }^{1}$, thereby improving the adsorption capacity of the electrodes after the regeneration stage [14].

As mentioned earlier, the presence of solid electrodes in CDI and MCDI results in salt adsorption being a discontinuous process (adsorption/desorption processes alternate). Moreover, since the solid electrodes are fixed and static on the current collector, the pores in the electrodes are limited. If the electrodes are saturated by the adsorption of ions, the deionization process cannot continue and the electrodes should be regenerated.

To overcome these limitations, the use of flow-electrode capacitive deionization (FCDI) process can be considered as a suitable option for water desalination. Unlike conventional CDI and MCDI cells where solid-type electrodes are fixed in the cells, FCDI uses the flow-electrode [27].

As shown in Fig. 1, the components of an FCDI cell generally include a pair of current collectors, cation and anion exchange membranes (IEMs), gasket and spacer chamber (water chamber), and a pair of end plates. In some FCDI systems, the current collectors also play the role of end plates [13].

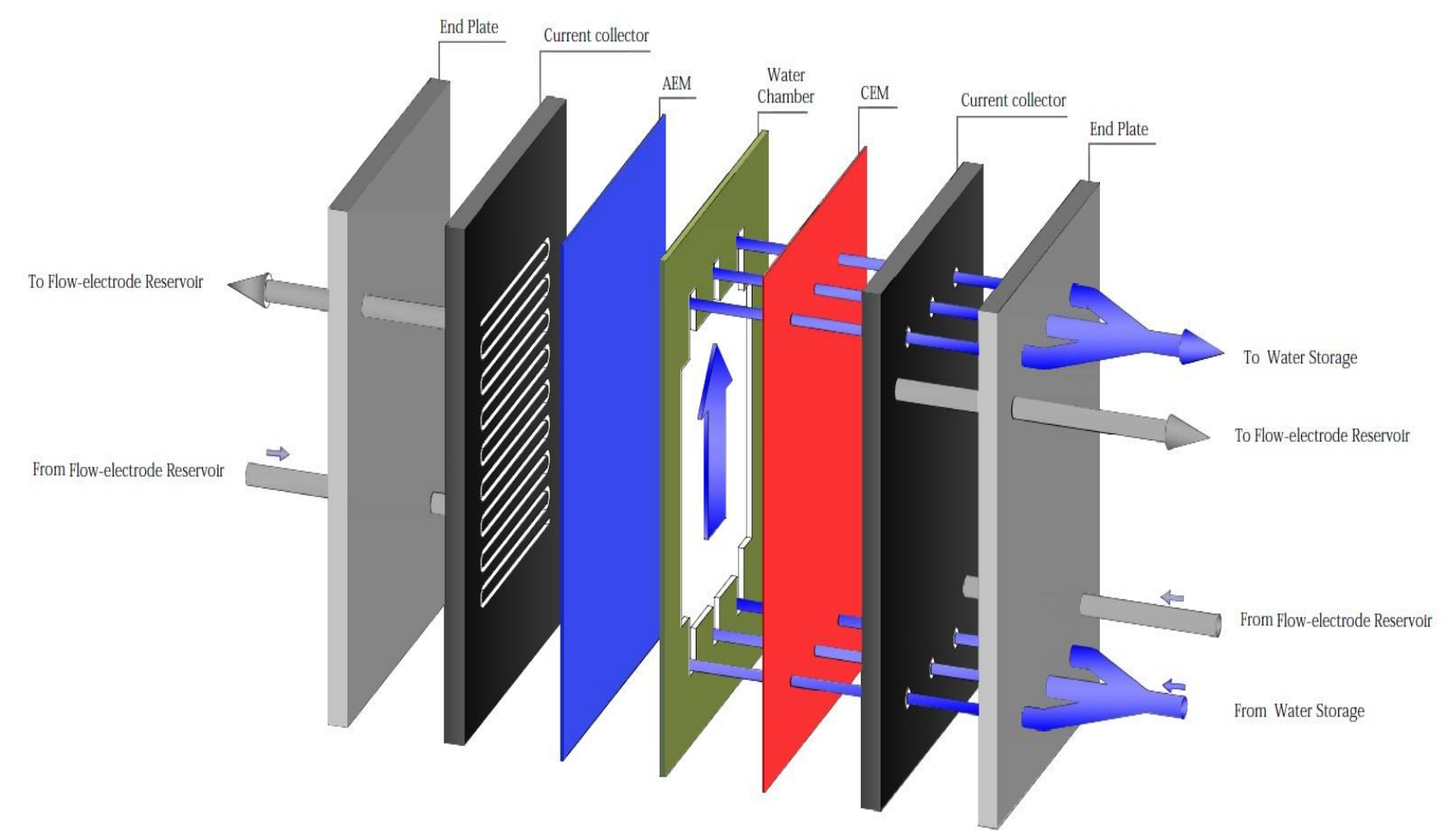

Fig. 1. General structure of an FCDI cell.

In FCDI, flow channels are carved on the current collector plates to provide a path for the movement of the flow-electrodes. In this process, the flow-electrodes flow between the IEMs and the current collectors [27]. In FCDI systems, the flow-electrodes can be used in two operational modes: open cycle operation (OC) mode and closed cycle operation (CC) mode.

1. The co-ion has the same charge as the electrode during ion removal, which is oppositely charged with the same electrode at the electrode regeneration stage [14]. 
In the OC mode, when the fresh flow-electrode is continuously injected into the FCDI cell, there is no reduction in the performance efficiency and the salt removal of FCDI cell, because in this mode, the flow-electrodes are continuously replaced and therefore, they have unlimited ion adsorption capacity.

Several laboratory studies in the field of FCDI have been conducted in the closed cycle operation mode and exploited the limited capacity of flow-electrodes in the experiments. In practical operation of flow-electrodes in FCDI systems, the flow-electrodes must be operated in the closed cycle operation (CC) modes using a limited capacity of flow-electrodes in FCDI systems due to high operation costs [27].

The CC modes of the flow-electrodes used in FCDI systems can also be divided into two categories: isolated closed cycle operation (ICC) mode and short-circuited closed cycle operation (SCC) mode. In the ICC mode of FCDI, the anode and cathode flow-electrodes are isolated and the FCDI system has two separate reservoirs for collecting and storing flowelectrodes called anodic and cathodic reservoirs. In other words, in ICC mode, anions and cations are adsorbed separately by anode and cathode flow-electrodes in a continuous manner and accumulated in the anodic and cathodic reservoirs, respectively. Unlike ICC mode, the flow-electrodes in SCC mode are only collected and stored in one reservoir. In other words, in SCC mode, the anode and cathode electrodes are continuously mixed and accumulated in a common reservoir during FCDI desalination operation. During desalination operation, when the flow-electrodes with limited capacities operate under ICC mode in the FCDI cell, the ion adsorption capacity of the cathodic and anodic flow-electrodes is gradually saturated. The desalination efficiency of the FCDI system is thus significantly reduced, as the ions separated from the feed water and transferred to the flow-electrodes are desorbed by the co-ions present in the flow-electrodes. This is similar to desalination operation using the conventional CDI technology. In contrast to the ICC mode of flow-electrodes in FCDI systems, the SCC mode with a flow-electrode with a limited capacity has continuous desalination operation without degradation of desalting efficiency. This is because in SCC mode in FCDI systems, salt ions in charged flow-electrodes are neutralized by simply mixing anode and cathode flow-electrodes and then regenerated. Unlike the deterioration of the ICC mode of FCDI desalination performance, no degradation of desalination performance was observed in the SCC mode with a limited capacity of flow-electrode [27].

The work of Paz Native et al. (2018) is one of the new achievements in the field of flowelectrode capacitive deionization (FCDI). They managed to take advantage of the FCDI process to separate monovalent and divalent cations $\left(\mathrm{Na}^{+}\right.$and $\left.\mathrm{Mg}^{2+}\right)$ and anions $\left(\mathrm{Cl}^{-}\right.$and $\left.\mathrm{SO}_{4}{ }^{2-}\right)$ from aqueous solutions. In fact, this process involves selective separation with ion-exchange and nanofiltration (NF) membranes [29]. This system consists of only one flow-electrode, which is recirculated between the holding vessel and two electrode compartments (flow-electrode). The electrode compartments are located between the electrodes and the membranes. The aqueous solution also contains $\mathrm{MgSo}_{4}$ and $\mathrm{NaCl}$, which is recirculated between the holding vessel and the FCDI module.

Another important factor contributing to the efficiency of an FCDI system is the material that used for flow electrode. Activated carbon is often used for this purpose. Some attempts have been also carried out to use other carbon materials such as carbon aerogels [30], [31], carbon 
black (CB) particles [32], Activated Charcoal [33]-[35], activated charcoal/commercial carbon black [36], [37] and activated carbon (AC)/MnO2 composite [38].

What was mentioned above together with numerous other recently-published research works reporting on the FCDI demonstrate the capabilities of this novel methodology in terms of continuous operability, high salt absorption capacity, excellent efficiency, cost-effectiveness, and environment-friendliness, so that it can address many of the architectural problems suffered by the CDI, making it a promising technology for the future of water desalination industry.

In this article, an attempt was made to identify the parameters affecting salt removal efficiency in an FDCI system and further evaluate the effect of each parameter in terms of intensity.

\section{Materials and methods}

\subsection{FCDI Setup and operating condition}

Fig. 2 shows the schematic experimental FCDI setup that we used in this experimental study. In the previous work [6], we tried to fully describe the structures, materials, assembling details, and operation of an FCDI system. In this experimental work, the same FCDI cell (with slight modifications) was used.

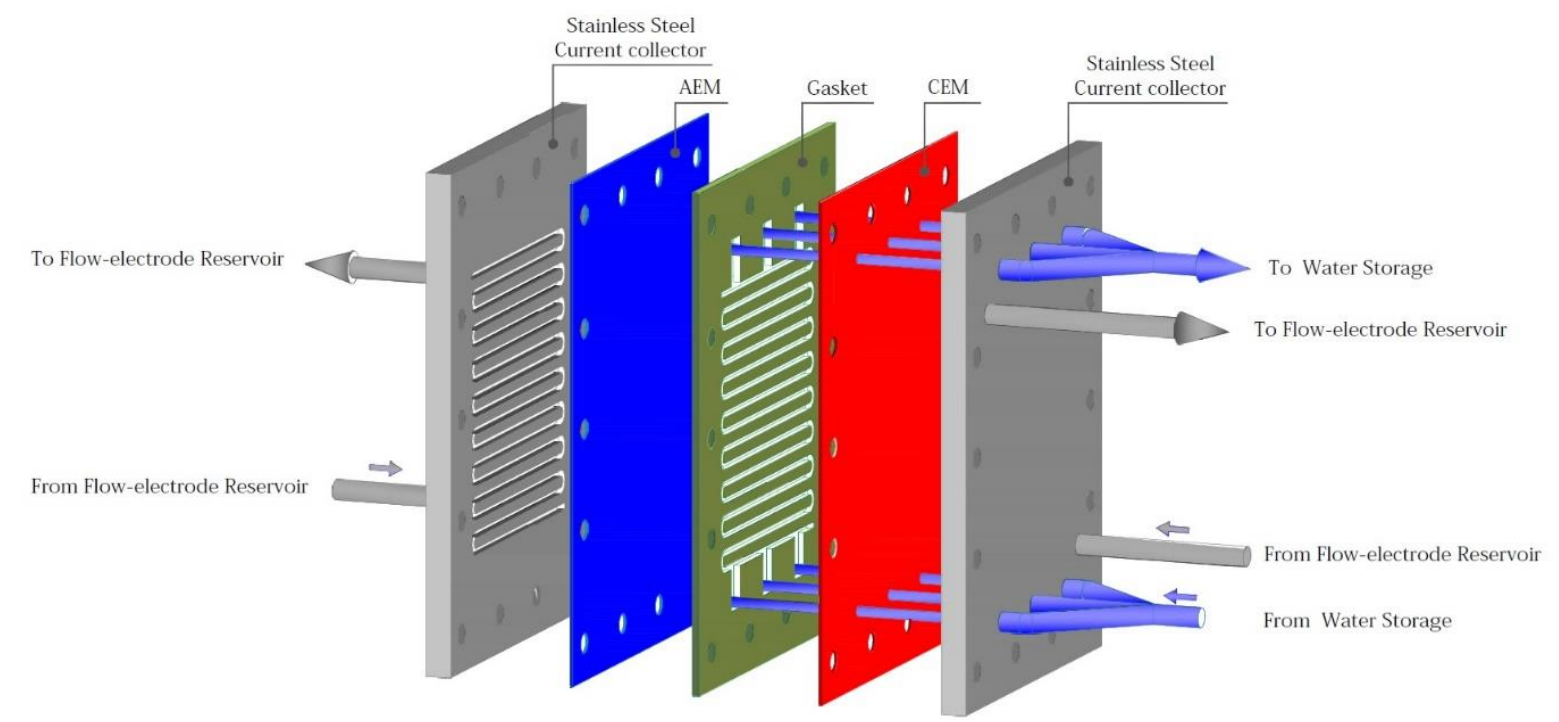

Fig. 2. Schematic arrangement of our FCDI cell components.

As shown in the Fig. 2, the unit cell of the FCDI system consists of a pair of stainless steel anodic and cathodic current collector plates (type 316) with dimensions $200 * 150 * 10 \mathrm{~mm}$, a pair of cation and anion exchange membranes with a thickness of $130 \mu \mathrm{m}$ (Fumasep FKS-PET130/ED-100 and Fumasep FAS-PET-130/ED-100 (Fumatech GmbH, Germany)), a spacer chamber or the water chamber including a PTFE (polytetrafluoroethylene) gasket (as shown in the Fig. 2) at the center of the FCDI cell. The meandering flow channels were carved on the current collector plates using the $\mathrm{CNC}$ engraving machine. 
The channels were intended as flow paths for suspension flow-electrodes. The width and depth of the flow channels are $2.5 \mathrm{~mm}$, the column length of the flow channel is $102.4 \mathrm{~mm}$, and each current collector plate consists of a total of 17 columns (as shown in Fig. 3).
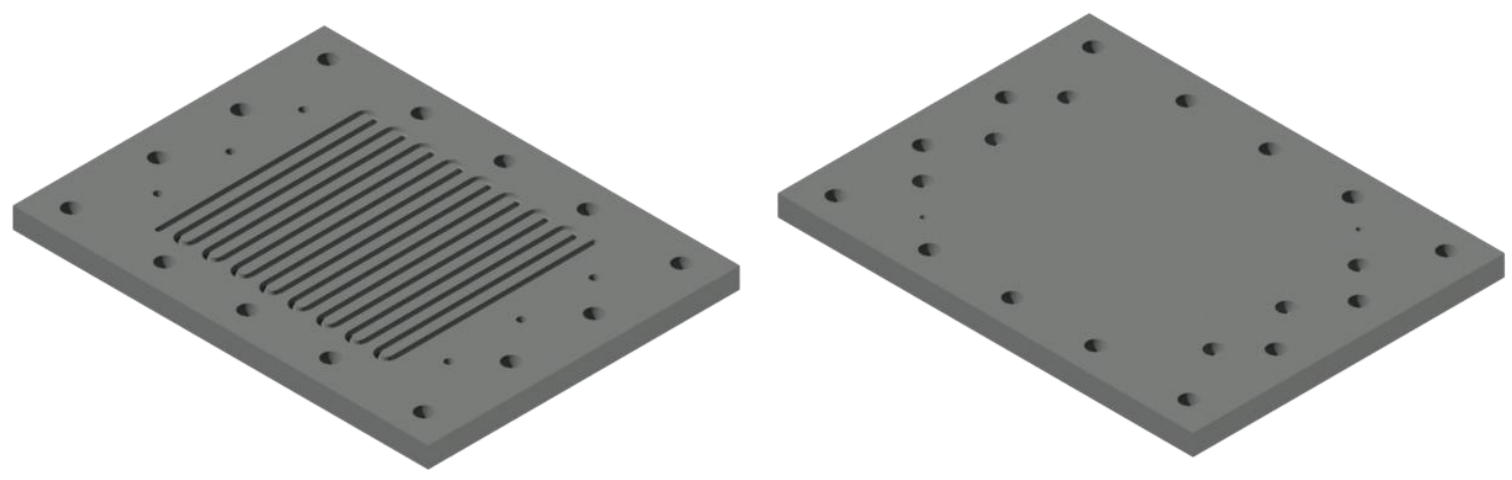

Fig. 3. Photographs of cathodic stainless steel current collector carved with meandering flow channels.

The contact area between the ion exchange membranes and the flow-electrodes is about 4352 $\mathrm{mm}^{2}$. All components of the FCDI cell were assembled with stainless steel nuts and bolts in the order shown in Fig. 2.

In all experiments, each reservoir of feed water and flow-electrodes contained $100 \mathrm{ml} \mathrm{NaCl}$ solution and about $250 \mathrm{ml}$ activated carbon suspension (as ion adsorbent), respectively. The particle size of the activated carbon powder (Norit, Netherlands) used in this experimental work is smaller than $5 \mu \mathrm{m}$.

In this FCDI system, the feed water and the suspension flow-electrodes are continuously recirculated between the reservoirs containing water and electrodes and the FCDI cell by means of the peristaltic pumps at the specified flow rates in the closed cycle operation (CC) mode. Consequently, each of the flow-electrodes enters the FCDI cell from the top of each current collector plate exits the cell after passing through the flow channels from the bottom of the current collector plates and returns to the same electrode reservoir. To neutralize and regenerate the flow-electrodes, both anode and cathode electrodes are returned to a reservoir and mixed. In other words, in this experimental study, the flow-electrodes operate in short-circuited closed cycle operation (SCC) mode. In each experiment, each of the flow-electrodes was divided equally between anodic and cathodic current collectors. The upper part of the flow-electrodes reservoir is the entry point of the two electrodes and the end of the reservoir is the exit point of the electrodes. Also, the feed water is pumped from the reservoir to the FCDI unit cell, and after passing through the flow channels, returns to the same water reservoir. Schematic layout 
diagram of flow-electrode capacitive deionization system in short-circuited closed cycle operation mode is shown in Fig. 4.

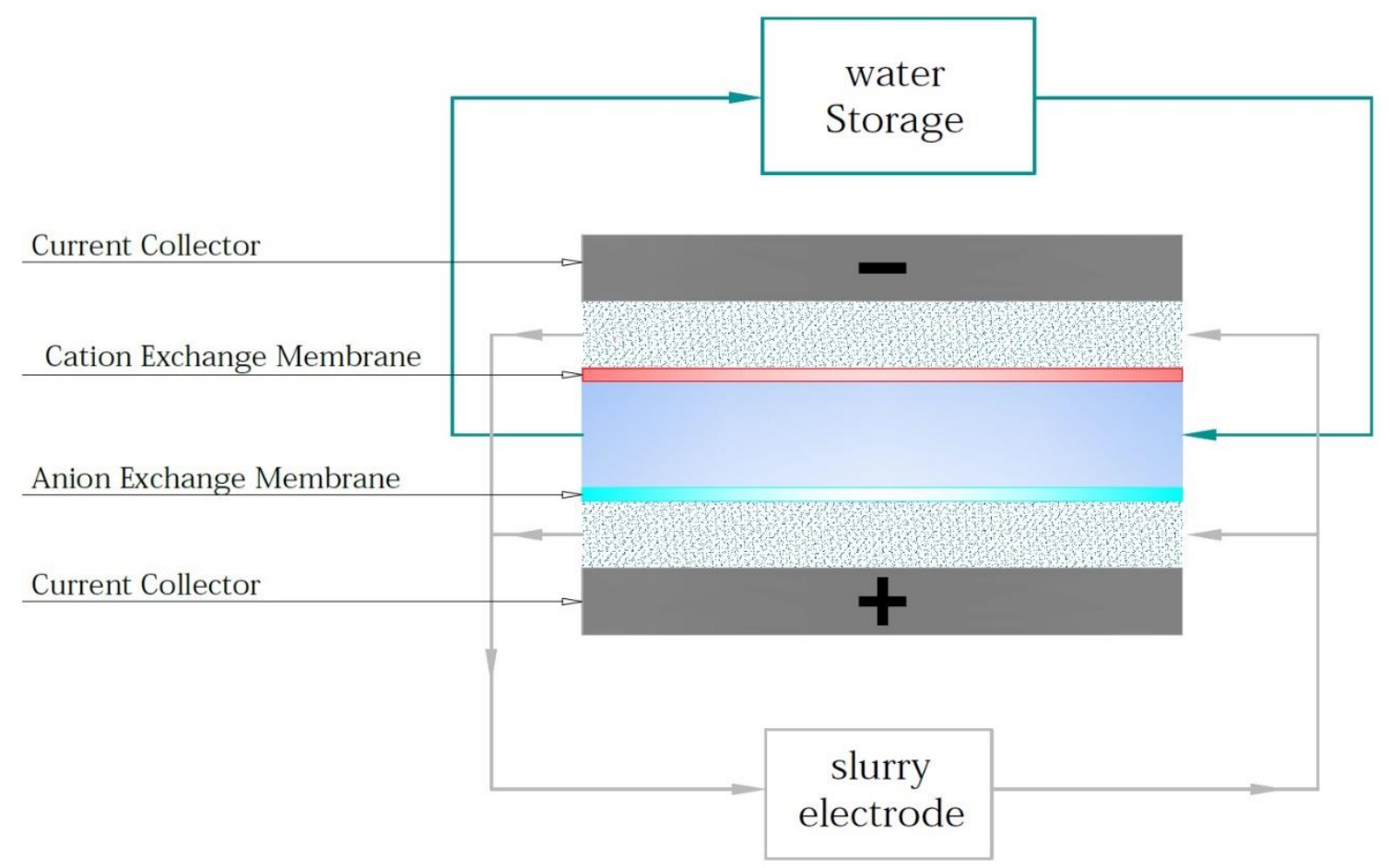

Fig. 4. Schematic layout diagram of flow-electrode capacitive deionization system in shortcircuited closed cycle operation mode.

Therefore, the feed water entering the FCDI system operates similarly to the flow-electrodes in closed cycle operation (CC) mode.

The closed cycle is repeated continuously for the feed water and the flow-electrodes to reduce the salt concentration of the feed water (electrical conductivity). In fact, the FCDI desalination system, which operates continuously in batch mode, can remove the salt ions from the feed water by means of the flow-electrodes until the desalination process reaches equilibrium (steady desalination). Since the changes in feed water salt concentration indicate a successful desalination process, the efficiency of salt removal from the feed water can be calculated using Equation (1):

$\operatorname{SRE}(\%)=\frac{C i-C f}{C i} * 100$

where $\mathrm{Ci}$ is the initial concentration of salt in the feed water and $\mathrm{Cf}$ is the final concentration of salt in the desalinated water.

Since the electrical conductivity of the feed water represents the concentration of salt in the feed water, the salt concentration of the desalinated water (water leaving the FCDI cell) was measured continuously using the conductivity meter (AZ 8603, Water Quality Meter, Taiwan). In addition, to supply the current collector plates with a cell voltage of $1.2 \mathrm{~V}$ in constant voltage mode (since voltages above $1.23 \mathrm{~V}$ lead to Faradaic reactions such as water hydrolysis [39][41]), we used GPS-3000 series constant voltage/current digital DC power supplies. 
Pneumatic and silicon tubing (outer diameter of $4 \mathrm{~mm}$ and inner diameter of $2 \mathrm{~mm}$ ) were used to establish a relationship between feed water and flow-electrodes reservoirs, peristaltic pumps, and FCDI cell.

\subsubsection{Settling and clogging of flow-electrodes in FCDI systems}

Since the activated carbon powder particles in the suspension electrode are susceptible to settling in the system, to prevent settling and clogging in this system and to create optimum homogeneity in the suspension electrode, a dispersant called carboxymethylcellulose (CMC) ( $4 \mathrm{~g} / 100 \mathrm{~g}$ activated carbon powder) was used as a suspension dispersant or stabilizer.

According to previous studies, to charge the cathode and anode suspension electrodes in the FCDI process, a voltage of $1.2 \mathrm{~V}$ is applied to the current collector plates to find the flowelectrodes of the adsorption potential of the counter-ions. Therefore, it is necessary to investigate the effect of the voltage applied to the dispersant of the suspension electrodes. For this purpose, a $15 \mathrm{wt} \%$ activated carbon suspension (distilled water with a volume of $250 \mathrm{ml}$, $37.5 \mathrm{~g}$ activated carbon powder, and $1.5 \mathrm{~g} \mathrm{CMC}$ ) was prepared and an electric voltage of $1.2 \mathrm{~V}$ was applied to the suspension using a DC power supply and two graphite plates. We observed that the electric voltage had no negative effect on the homogeneity of the activated carbon suspension, nor did it lead to coagulation and settling. Therefore, CMC can be used as a dispersant in the preparation of suspension electrodes.

\subsection{Description of experiments}

We conducted the FCDI experiments to investigate the effect of three operating parameters, namely flow rate of flow-electrodes, electrolyte salt concentration of flow-electrodes, and initial feed water concentration, on the efficiency of desalination operation. In all experiments, the flow-electrodes with a volume of approximately $250 \mathrm{ml}$ and identical carbon mass loading ( $5 \mathrm{wt} \%$ activated carbon powder suspension electrode) were recirculated between the electrodes reservoir and the FCDI unit cell. Also, in all experiments, $100 \mathrm{ml}$ of the feed water containing $\mathrm{NaCl}$ with the same constant flow rate of $20 \mathrm{ml} / \mathrm{min}$ was recirculated between the feed water reservoir and the FCDI cell. To investigate the effect of the three above mentioned parameters on the desalination efficiency of the FCDI system, according to Table 4, we conducted six experiments and compared the results in the diagrams. The results of this comparison can be seen in section 3 .

In all FCDI experiments performed in this study, we allowed the water and flow-electrodes to recirculate in the FCDI system for 15 minutes at the beginning of the work and after the FCDI system was turned on (the pumps of the feed water and flow-electrodes were turned on) and before the voltage was applied to the current collector plates. The circulation of water and flowelectrodes in the system slightly decreased the amount of salt ions in the water reservoir and reached a constant and unchanged concentration (equilibrium). This can be justified by two reasons:

1. At the end of each FCDI experiment, the system was washed with distilled water to prevent the activated carbon particles from accumulating in the system and, consequently, to avoid reducing the desalination efficiency of the system. Therefore, the distilled water remaining in the FCDI system influences the feed water concentration in the next experiment. In the experiments, the volume of distilled water in the system was estimated to be $18.4 \mathrm{ml}$. 
2. The nature of the FCDI desalination process is defined mainly based on the electrosorption of ions on porous materials under an electric potential. Also, the efficiency of the desalination operation is influenced by the osmotic phenomenon caused by the difference in salt concentration between the flow-electrodes and the feed water [26], [42]. However, the effect of chemical ion adsorption is negligible compared to desalination because of the voltage applied to the current collector plates.

To prevent clogging and deposition on the surface and in the channels of the current collector plates, a reverse voltage (polarity reversal) was applied to the current collector plates after removing the salt ions in the desired amount at the end of each experiment. This operation has two advantages: regeneration of the flow-electrodes, and improved performance of the current collector plates. By reversing the poles, feed water deionization is reversed and the ions removed from the feed water, return again to the feed water reservoir. Thus, the flow-electrodes, which previously adsorbed the salt ions, return the ions to water and are regenerated. At this stage, the activated carbon powder deposits that detach from the inner channel surface of the current collector plates return to the reservoir of the flow-electrodes.

In all six FCDI experiments, by applying a voltage of $1.2 \mathrm{~V}$ to the FCDI cell and starting the salt removal process in a fixed period of 5 hours, we achieved a certain amount of $\mathrm{EC}(\mathrm{NaCl})$ removal. Then, at the end of each experiment, we applied a reverse voltage (discharge at -1.2 V) to the FCDI cell. We applied the reverse voltage in each experiment until the flow-electrodes returned all the salt adsorbed from the feed water back into the water channel and then into the water reservoir, and the salt concentration (EC) of the desalinated water in the reservoir reached the initial value. Thus, at the second stage of each experiment, the FCDI system was given time to recover all the $\mathrm{NaCl}$ ions removed at the first stage and to actually perform the regeneration (neutralization) of the flow-electrodes. We repeated each of the six experiments four times and discarded the outlier data. In the FCDI experiments, laboratory errors (including the errors in the equipment used, measurement errors, laboratory conditions, and power fluctuations) can have a negative effect on the outcome of each experiment. Therefore, we tried to choose the most accurate and correct experiment to evaluate the efficiency of the FCDI system in removing the EC from the feed water.

To investigate the effect of flow rate of flow-electrodes, initial concentration of feed water, and electrolyte salt concentration of flow-electrodes on $\mathrm{NaCl}$ adsorption efficiency, the first to sixth experiments were compared in separate diagrams, as shown in Tables 1 to 3.

\section{Table 1. Effect of flow rate of flow-electrodes on salt adsorption (removal) efficiency of} FCDI system

\begin{tabular}{|c|c|}
\hline Test No. & Purpose of comparison \\
\hline 1 and 2 & $\begin{array}{c}\text { Effect of flow rate of flow-electrodes on salt adsorption efficiency in low } \\
\text { feed water concentrations and low electrolyte salt concentration of flow- } \\
\text { electrodes }\end{array}$ \\
\hline 3 and 4 & $\begin{array}{c}\text { Effect of flow rate of flow-electrodes on salt adsorption efficiency in high } \\
\text { feed water concentrations and low electrolyte salt concentration of flow- } \\
\text { electrodes }\end{array}$ \\
\hline 5 and 6 & $\begin{array}{c}\text { Effect of flow rate of flow-electrodes on salt adsorption efficiency in high } \\
\text { feed water concentrations and high electrolyte salt concentration of flow- } \\
\text { electrodes }\end{array}$ \\
\hline
\end{tabular}


Table 2. Effect of initial sodium chloride concentration of feed water on salt adsorption (removal) efficiency of FCDI system

\begin{tabular}{|c|l|}
\hline Test No. & \multicolumn{1}{|c|}{ Purpose of comparison } \\
\hline 2 and 4 & $\begin{array}{l}\text { Effect of initial sodium chloride concentration of feed water on salt } \\
\text { adsorption efficiency at low rates of flow-electrodes and low electrolyte salt } \\
\text { concentration of flow-electrodes }\end{array}$ \\
\hline 1 and 3 & $\begin{array}{l}\text { Effect of initial sodium chloride concentration of feed water on salt } \\
\text { adsorption efficiency at high rates of flow-electrodes and low electrolyte } \\
\text { salt concentration of flow-electrodes }\end{array}$ \\
\hline
\end{tabular}

Table 3. Effect of salt concentration of electrolyte of flow-electrodes on salt adsorption (removal) efficiency of FCDI system

\begin{tabular}{|c|l|}
\hline Test No. & \multicolumn{1}{c|}{ Purpose of comparison } \\
\hline 3 and 6 & $\begin{array}{l}\text { Effect of salt concentration of flow-electrodes on salt adsorption efficiency in } \\
\text { high feed water concentrations and high flow rate of flow-electrodes }\end{array}$ \\
\hline 4 and 5 & $\begin{array}{l}\text { Effect of salt concentration of flow-electrodes on salt adsorption efficiency in } \\
\text { high feed water concentrations and low flow rate of flow-electrodes }\end{array}$ \\
\hline
\end{tabular}

\section{Results and discussion}

In this section, we review, explain and compare the results of the FCDI experiments and perform the statistical and graphical analysis.

\subsection{Diagram and results of FCDI experiments conducted in this study}

Table 4. Summary of specifications and results of FCDI experiments conducted in this experimental study

\begin{tabular}{|c|c|c|c|c|c|c|c|}
\hline $\begin{array}{c}\text { Test } \\
\text { No. }\end{array}$ & $\begin{array}{c}\text { Initial } \\
\text { concentration } \\
\text { of feed water } \\
(\mathrm{mg} / \mathrm{l})\end{array}$ & $\begin{array}{c}\text { Initial } \\
\text { electrical } \\
\text { conductivity } \\
\text { of influent } \\
\text { saltwater } \\
\left.(\mathrm{mScm})^{-1}\right)\end{array}$ & $\begin{array}{c}\text { Flow rate } \\
\text { of flow- } \\
\text { electrodes } \\
(\mathrm{ml} / \mathrm{min})\end{array}$ & $\begin{array}{c}\text { Concentration } \\
\text { of } \mathrm{NaCl} \text { in } \\
\text { electrolyte of } \\
\text { flow- } \\
\text { electrodes } \\
(\mathrm{M}, \text { molarity) }\end{array}$ & $\begin{array}{c}\text { Salt } \\
\text { removal } \\
\text { efficiency }\end{array}$ & $\begin{array}{c}\text { Salt } \\
\text { adsorption } \\
\text { capacity } \\
\text { (SAC) } \\
(\mathrm{mg} / \mathrm{g} \text { dry } \\
\text { carbon })\end{array}$ & $\begin{array}{c}\text { Duration } \\
\text { of } \\
\text { reverse } \\
\text { voltage } \\
\text { applied } \\
\text { to FCDI } \\
\text { system } \\
\text { (hr) }\end{array}$ \\
\hline 1 & 1000 & 2.09 & 80 & 0.1 & $83 \%$ & 7.36 & 2 \\
\hline 2 & 1000 & 2.07 & 40 & 0.1 & $81 \%$ & 7.2 & 2 \\
\hline 3 & 5000 & 8.01 & 80 & 0.1 & $49 \%$ & 18.8 & 3 \\
\hline 4 & 5000 & 8.02 & 40 & 0.1 & $54 \%$ & 20.64 & 3.25 \\
\hline 5 & 5000 & 8.02 & 40 & 0.3 & $71 \%$ & 26.96 & 2.5 \\
\hline 6 & 5000 & 8.05 & 80 & 0.3 & $72 \%$ & 29.12 & 3 \\
\hline
\end{tabular}

\subsubsection{Effect of flow rate of flow-electrodes on salt adsorption (removal) efficiency of FCDI system}

By comparing the results of two experiments 1 and 2, we examined the effect of flow rate of flow-electrodes on the adsorption efficiency of $\mathrm{NaCl}$ at low initial concentrations $(1000 \mathrm{mg}$ 
$\mathrm{NaCl} / \mathrm{l})$ of feed water and low concentrations $(0.1 \mathrm{M} \mathrm{NaCl})$ of salt in the electrolyte of flowelectrodes.

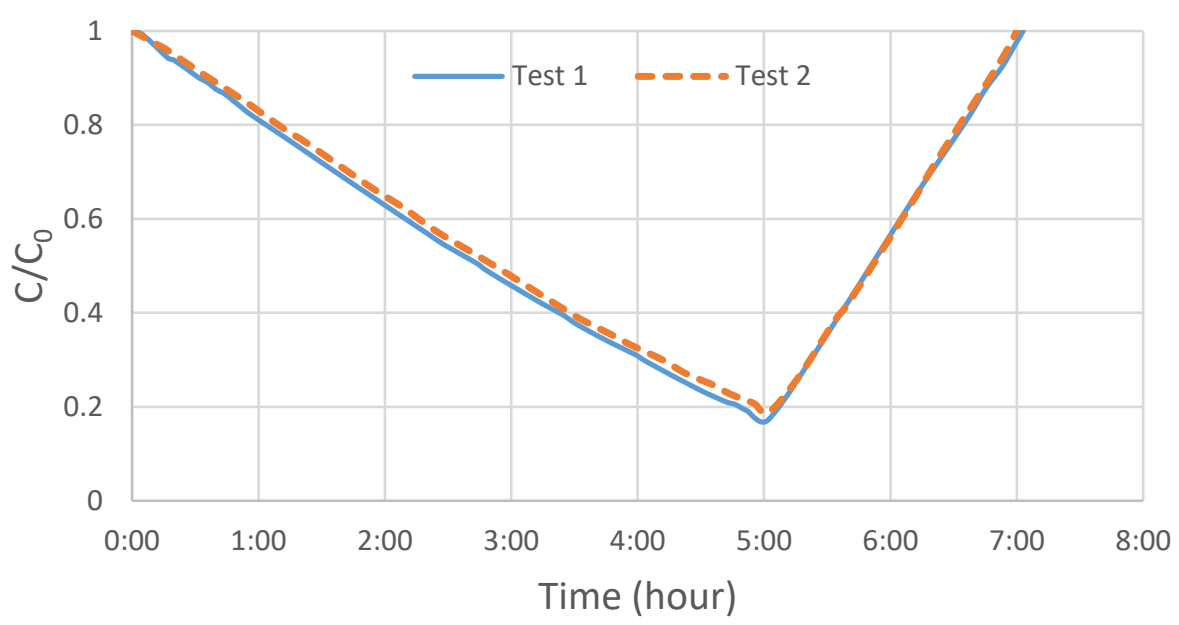

Fig. 5. Result comparison of experiments 1 and 2.

According to Table 4, since the two experiments 1 and 2 differed only in the flow rate of the flow-electrodes and the results of the two experiments were almost the same, it can be concluded that the flow rate of the flow-electrodes at low initial concentrations $(1000 \mathrm{mg}$ $\mathrm{NaCl} / \mathrm{l})$ of the feed water and low concentrations $(0.1 \mathrm{M} \mathrm{NaCl})$ of the salt in the electrolyte of the flow-electrodes had no significant effect on the salt removal efficiency of the FCDI system.

By comparing the results of two experiments 3 and 4, we examined the effect of flow rate of flow-electrodes on the adsorption efficiency of $\mathrm{NaCl}$ at high initial concentrations $(5000 \mathrm{mg}$ $\mathrm{NaCl} / \mathrm{l})$ of feed water and low concentrations $(0.1 \mathrm{M} \mathrm{NaCl})$ of salt in the electrolyte of flowelectrodes.

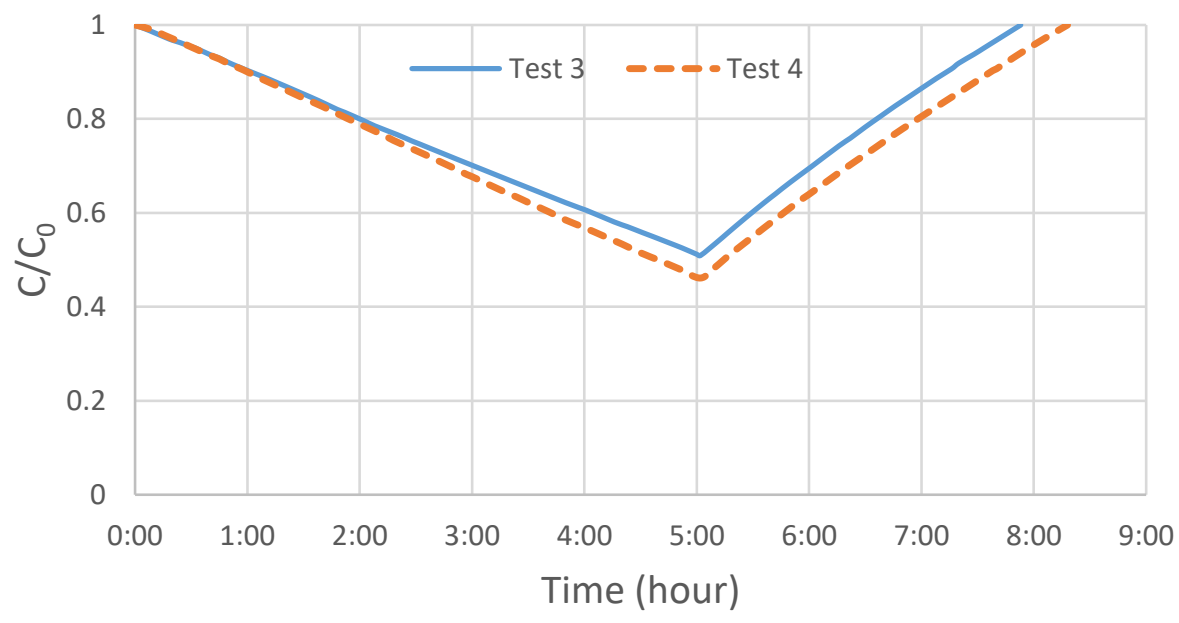


Fig. 6. Result comparison of experiments 3 and 4.

Comparing experiments 3 and 4, the effect of the flow rate of the flow-electrodes on the EC removal efficiency of the feed water with a high initial concentration $(5000 \mathrm{mg} \mathrm{NaCl} / \mathrm{l})$ was investigated. In contrast to experiments 1 and 2 for the feed water with a low initial concentration $(1000 \mathrm{mg} \mathrm{NaCl} / \mathrm{l})$, where the effect of the flow rate of the flow-electrodes on the salt removal efficiency was insignificant and negligible, the salt removal efficiency of the flowelectrodes in both experiments 3 and 4 showed a meaningful difference. In addition, the lower flow rate $(40 \mathrm{ml} / \mathrm{min})$ of the flow-electrodes resulted in a higher EC removal efficiency (54\%). In experiment 4 , the residence time of the flow-electrodes $(40 \mathrm{ml} / \mathrm{min})$ in the FCDI system is higher than in experiment 3, resulting in a higher EC removal efficiency. This is because the flow-electrodes have more opportunity to remove salt ions from the feed water at a higher residence time.

By comparing the results of two experiments 5 and 6 , we examined the effect of flow rate of flow-electrodes on the adsorption efficiency of $\mathrm{NaCl}$ at high initial concentrations $5000 \mathrm{mg}$ $\mathrm{NaCl} / \mathrm{l})$ of feed water and high concentrations $(0.3 \mathrm{M} \mathrm{NaCl})$ of salt in the electrolyte of flowelectrodes.

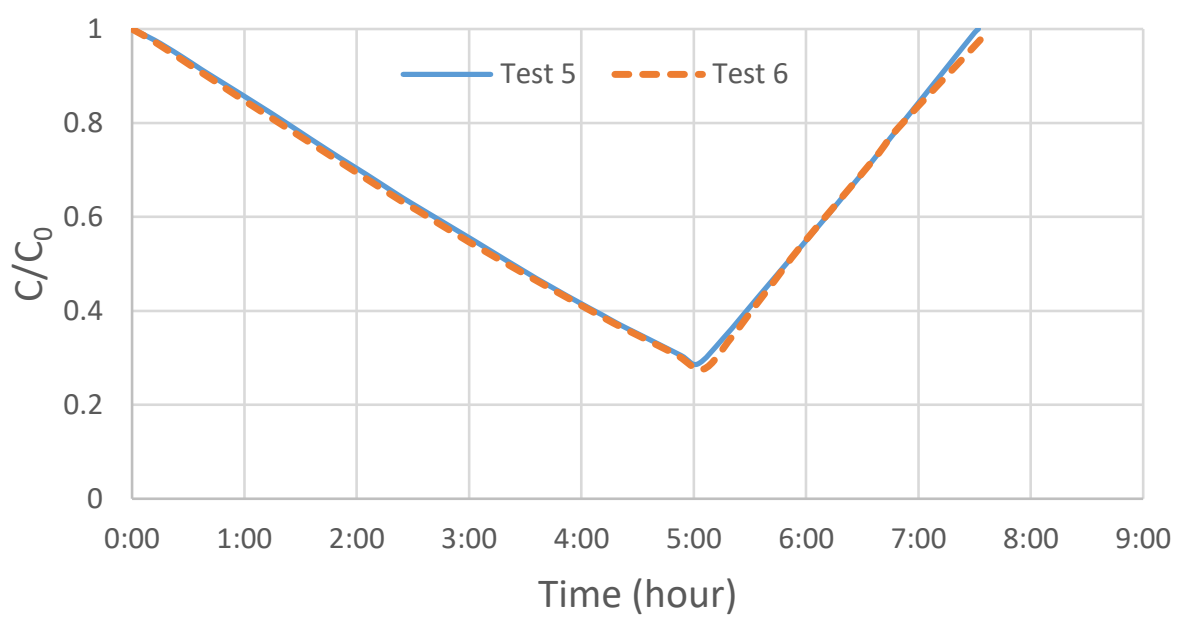

Fig. 7. Result comparison of experiments 5 and 6.

Considering the agreement between the results of both experiments 5 and 6 , it can be concluded that at higher $\mathrm{NaCl}$ concentrations $(0.3 \mathrm{M})$ in the electrolyte of the flow-electrodes, the flow rate of the flow-electrodes lost its effect on the desalination efficiency of the FCDI system and the obtained results of both experiments were almost the same. In fact, the results of the FCDI experiments did not differ at either the low or high flow rate of the flow-electrodes. We concluded that probably at high initial concentrations of the feed water $(5000 \mathrm{mg} \mathrm{NaCl} / \mathrm{l})$ and higher $\mathrm{NaCl}$ concentration $(0.3 \mathrm{M})$ in the electrolyte of the flow-electrodes, the effect of electrode flow rate is negligible. Therefore, the flow rates did not significantly change the outcome of the process. In fact, in the two experiments, it appears that the ion exchange capacity between the flow-electrodes and the feed water can overcome the residence time effect of the feed water in the system. 


\subsubsection{Effect of initial sodium chloride concentration of feed water on salt adsorption (removal) efficiency of FCDI system}

By comparing the results of both FCDI experiments 2 and 4 in Fig. 8, we examined the effect of the initial sodium chloride concentration of the feed water on $\mathrm{NaCl}$ adsorption efficiency at low rates $(40 \mathrm{ml} / \mathrm{min})$ of the flow-electrodes and low concentrations $(0.1 \mathrm{M} \mathrm{NaCl})$ of $\mathrm{NaCl}$ in the electrolyte of the flow-electrodes.

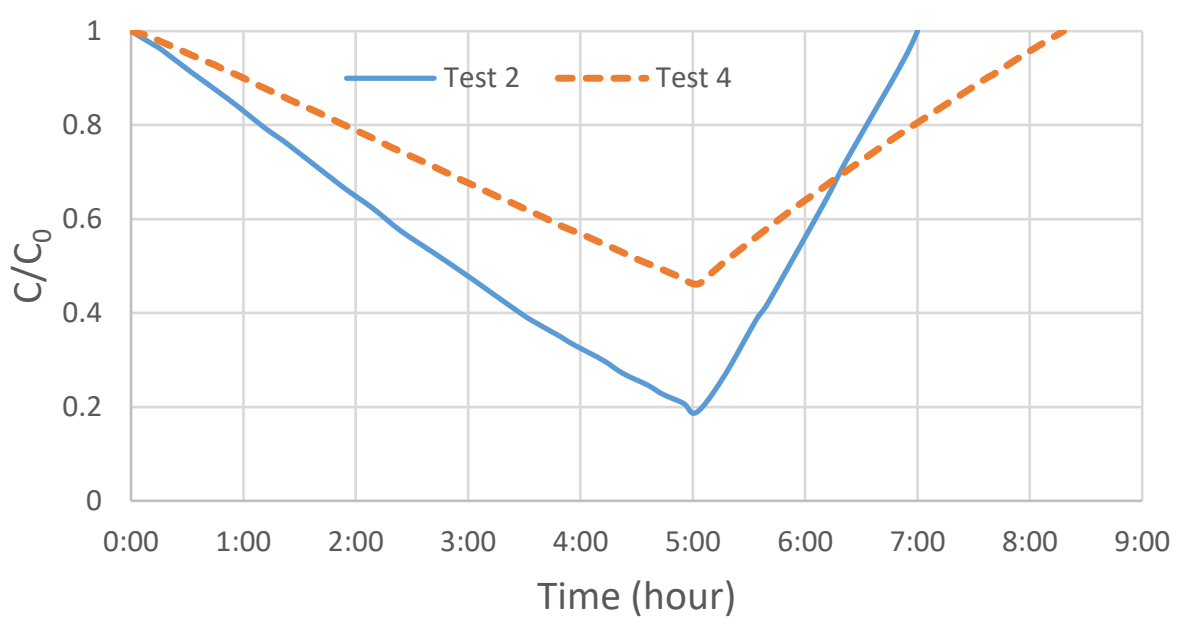

Fig. 8. Result comparison of experiments 2 and 4.

According to Fig. 8, the $\mathrm{NaCl}$ removal efficiency in experiment $2(81 \%)$ was much higher than that in experiment 4 (54\%), indicating the significant effect of the initial feed water concentration on the $\mathrm{NaCl}$ adsorption efficiency of the desired FCDI system. In both experiments, the flow rate of the flow-electrodes was $40 \mathrm{ml} / \mathrm{min}$ and the concentration of $\mathrm{NaCl}$ in the electrolyte of the flow-electrodes was $0.1 \mathrm{M}$. Since the slope of the $\mathrm{NaCl}$ removal diagram in the first phase of experiment 2 is higher than in experiment 4 , the diagram slope in the second phase of the FCDI experiment, which involves polarity reversal and electrodes regeneration, is higher in experiment 2 than in experiment 4 . In these two experiments all the parameters are the same, only the initial concentration of $\mathrm{NaCl}$ is lower in experiment 2 than in experiment 4 and thus, the achieved salt removal efficiency was higher in experiment 2 than in experiment 4. In the electrode regeneration phase, the flow-electrodes in experiment 2 were able to return the same amount of salt that they had adsorbed in the first phase in a shorter time. This is because the flow-electrodes adsorbed less salt in experiment 2 than in experiment 4 and then returned to water, and consequently consumed less ion adsorption capacity. In this way, the process of ion adsorption and electrode regeneration was represented in the diagram with a steeper slope than in experiment 4. According to Table 4, the amount of SAC in experiment 4 was approximately 3 times that in experiment 2 , since the initial feed water concentration in experiment 4 is significantly more than the initial feed water concentration in experiment 2 .

The Fig. 9 shows the effect of initial feed water concentration on $\mathrm{NaCl}$ adsorption efficiency in the desired FCDI system at high flow rates $(80 \mathrm{ml} / \mathrm{min})$ of the flow-electrodes and low $\mathrm{NaCl}$ 
concentrations $(0.1 \mathrm{M})$ in the electrolyte of the flow-electrodes. For this purpose, we plotted the results of both experiments 1 and 3 on a diagram as shown in Fig. 9.

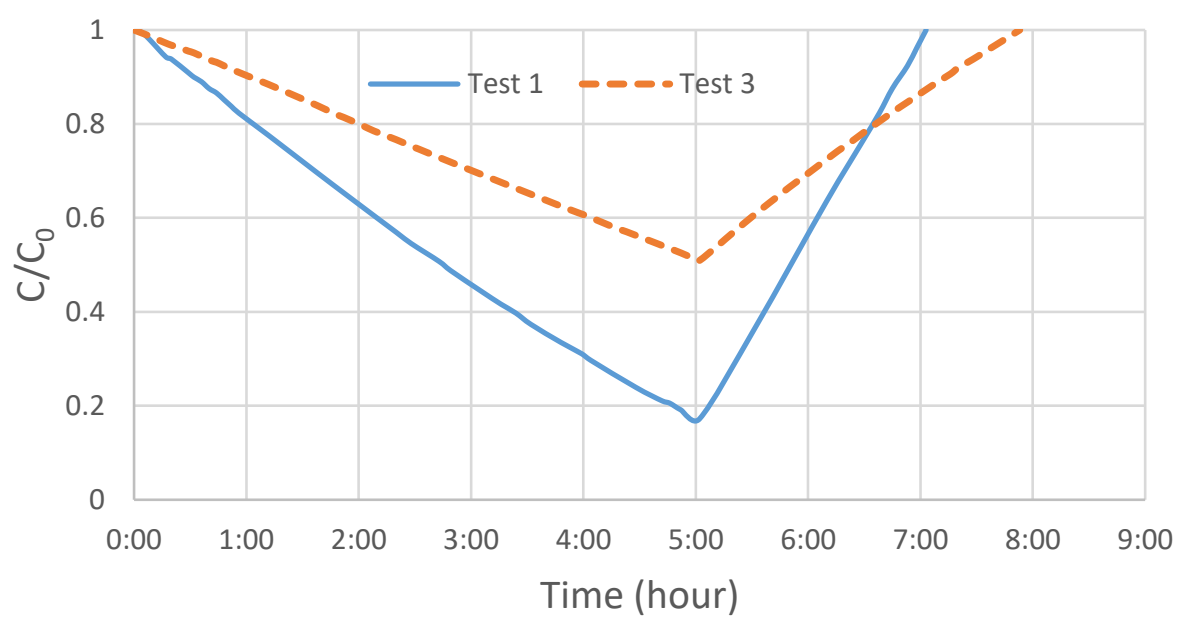

Fig. 9. Result comparison of experiments 1 and 3.

It is evident from the Fig. 9 that the salt adsorption efficiency was higher (83\%) in experiment 1 than in experiment 3 (49\%). As mentioned earlier, experiments 1 and 3 differed only in the initial feed water concentration and the other conditions were considered to be the same in both experiments. The amount of SAC was $7.36 \mathrm{mg} / \mathrm{g}$ dry carbon in experiment 1 and $18.8 \mathrm{mg} / \mathrm{g}$ dry carbon in experiment 3 . The marked difference between the two values obtained is due to the marked difference between the initial $\mathrm{NaCl}$ concentration in the feed water in experiments 1 and 3. For the experiment with the feed water at a higher initial salt concentration, it is reasonable to achieve a lower salt adsorption efficiency and a higher SAC. As shown in the Fig. 9, the diagram slope of experiment 3 in both phases of adsorption (removal of $\mathrm{NaCl}$ ions) and desorption (regeneration of flow-electrodes and return of adsorbed $\mathrm{NaCl}$ ions to the feed water reservoir) of $\mathrm{NaCl}$ ions is lower than in experiment 1 .

To effectively remove salt from the FCDI system, the ions in the feed water must first pass through the ion-exchange membrane and enter the flow-electrodes. The ions are adsorbed in the microporous and mesoporous spaces of the activated carbon and finally removed from the FCDI system. A number of previous studies on the electrical adsorption of ions on the microporous spaces of carbon electrodes reported that the electrical adsorption increased as salt concentration in the flow-electrodes increased. This is due to the overlapping effect of the electrical double layer (EDL) on the microporous spaces and the reduced ionic resistance at higher salt concentrations.

It was found that sodium chloride removal increases with increasing feed water concentration, resulting from stronger electrostatic interactions, higher concentration gradient, and less double layer overlapping effect [43].

Therefore, EDL overlapping is a key factor affecting capacitive behavior and electrosorption capacity [44]-[46]. 


\subsubsection{Effect of salt concentration of electrolyte of flow-electrodes on salt adsorption (removal) efficiency of FCDI system}

Comparing the results of experiments 3 and 6 in a diagram (Fig. 10) illustrates the importance of the salt concentration in the electrolyte of the flow-electrodes (molarity) on the salt adsorption efficiency of the FCDI system at a high concentration $(5000 \mathrm{mg} \mathrm{NaCl} / \mathrm{l})$ of the feed water and a high flow rate of the flow-electrodes $(80 \mathrm{ml} / \mathrm{min})$.

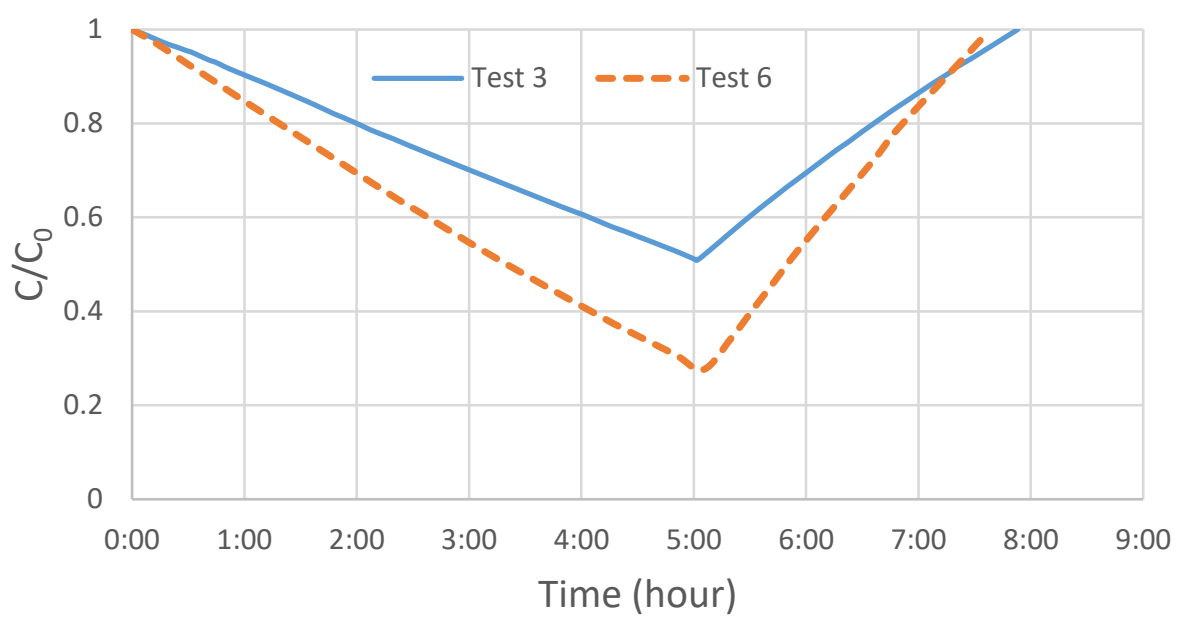

Fig. 10. Result comparison of experiments 3 and 6.

As shown in Table 4, the initial concentration of the feed water $(5000 \mathrm{mg} \mathrm{NaCl} / \mathrm{l})$ and the flow rate of the flow-electrodes $(80 \mathrm{ml} / \mathrm{min})$ are the same in both experiments. The two experiments differ only in the salt concentration (molarity) in the electrolyte of the flow-electrodes. The difference in the molarity of the electrolyte in experiments 3 and 6 made a significant difference in $\mathrm{NaCl}$ adsorption efficiency (about 23\%) and the amount of SAC (about $10 \mathrm{mg} \mathrm{NaCl} / \mathrm{gr}$ dry carbon). In fact, it can be concluded that the salt concentration in the electrolyte of the flowelectrodes has a direct effect on the salt adsorption efficiency of the FCDI system.

To investigate the importance of the salt concentration in the electrolyte of the flow-electrodes on the salt adsorption efficiency of our FCDI system, in addition to comparing the results of experiments 3 and 6, the results of experiments 4 and 5 were also compared in a diagram (as shown in Fig. 11). 


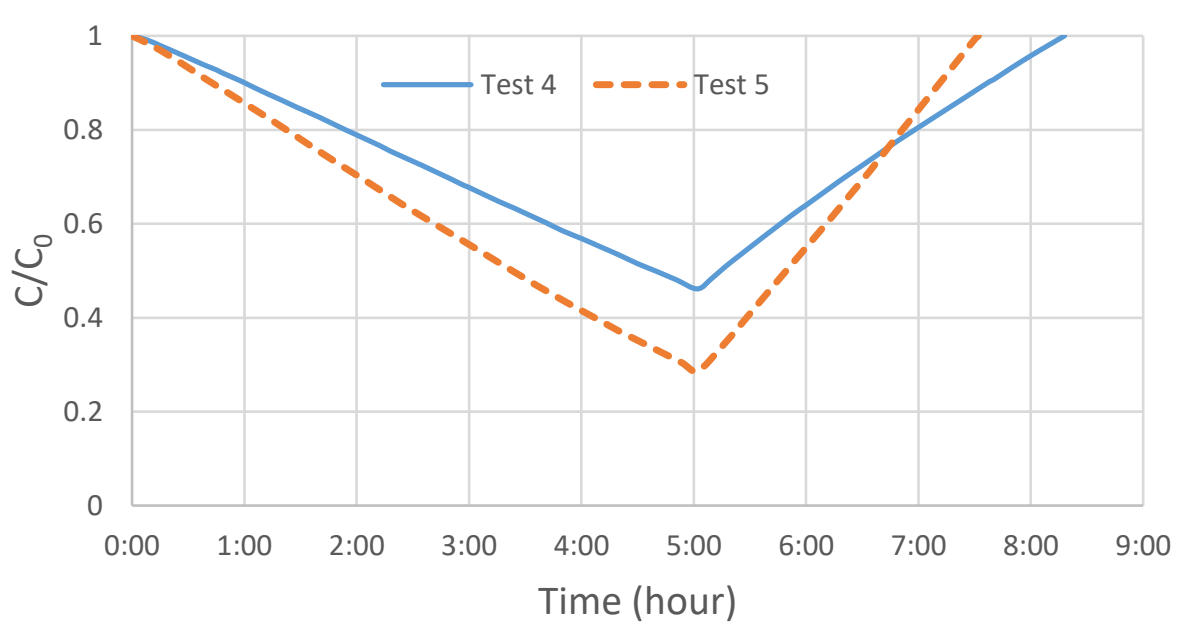

Fig. 11. Result comparison of experiments 4 and 5.

According to the data in Table 4, the initial concentration of the feed water and the flow rate of the flow-electrodes are the same in experiments 4 and 5, and the two experiments differ only in the salt concentration in the electrolyte.

As shown in Table 4, since the salt concentration in the electrolyte of the flow-electrodes in experiment $4(0.1 \mathrm{M} \mathrm{NaCl})$ is lower than the value specified in experiment $5(0.3 \mathrm{M} \mathrm{NaCl})$, the $\mathrm{NaCl}$ adsorption efficiency in experiment $4(54 \%)$ was lower than that in experiment $5(71 \%)$. As mentioned earlier, the desalination efficiency of the FCDI system is influenced by both the electrical potential and the osmotic phenomenon caused by the difference in the salt concentration of the flow-electrode and the salt water [26], [42].

In addition to salt adsorption efficiency, the SAC value was also lower in experiment 4 (20.64 $\mathrm{mg} \mathrm{NaCl} / \mathrm{gr}_{\text {dry carbon}}$ ) than in experiment 5 (26.96 $\mathrm{mg} \mathrm{NaCl} / \mathrm{gr}_{\text {dry carbon}}$ ).

According to Table 4, it can be found that the difference of SAC value obtained from

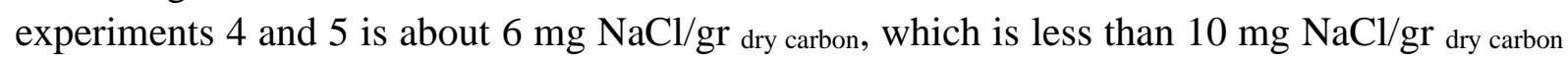
(difference of SAC value obtained from experiments 3 and 6), because the flow rate of electrodes in experiments 4 and $5(40 \mathrm{ml} / \mathrm{min})$ was lower than the flow rate of electrodes in experiments 3 and $6(80 \mathrm{ml} / \mathrm{min})$. The difference in electrode flow rate (as shown in Table 4) caused the difference in $\mathrm{NaCl}$ adsorption efficiency in paired experiments 3-6 (about 23\%) and 4-5 (about 17\%).

\section{Conclusions}

The aim of this study was to experimentally explore the performance of a pilot FCDI system at the laboratory scale and evaluate the effects of three parameters of flow rate of flow-electrodes, electrolyte salt concentration of flow-electrodes, and initial feed water concentration on the desalination efficiency. Six experiments were carried out on this FCDI system under closedcycle continuous mode of operation. 
The flow-electrodes operated in short-circuited closed-cycle operation (SCC) mode and the feedwater entering the FCDI system operated in closed-cycle operation (CC) mode.

Overall, it can be said that in these experiments, the flow rate of the flow electrode did not make a considerable change in the salt removal efficiency and its impact was only observed when the initial concentration of the feed water was high $(5000 \mathrm{mg} \mathrm{NaCl} / \mathrm{l})$ and the salt concentration of the electrolyte (in the flow-electrodes) was low $(0.1 \mathrm{M} \mathrm{NaCl})$. At the mentioned conditions, the low flow rate of the flow-electrodes slightly enhanced the salt removal efficiency.

The highest salt removal efficiency $(83 \%)$ was observed in the experiment involving $5 \mathrm{wt} \%$ suspension electrode with the flow rate of $80 \mathrm{ml} / \mathrm{min}$, low salt concentration $(0.1 \mathrm{M} \mathrm{NaCl})$ in the electrolyte of flow-electrode, and $100 \mathrm{ml}$ feed water with an initial concentration of 1000 $\mathrm{mg} \mathrm{NaCl} / 1$ and flow rate of $20 \mathrm{ml} / \mathrm{min}$ in 5 hours.

The highest SAC (29.12 mg/g dry carbon) was also achieved in the experiment which involved $5 \mathrm{wt} \%$ suspension electrode with the flow rate of $80 \mathrm{ml} / \mathrm{min}$, high $\mathrm{NaCl}$ concentration $(0.3 \mathrm{M}$ $\mathrm{NaCl}$ ) of the electrolyte of flow-electrode, and $100 \mathrm{ml}$ feed water with an initial concentration of $5000 \mathrm{mg} \mathrm{NaCl} / 1$ and flow rate of $20 \mathrm{ml} / \mathrm{min}$ in 5 hours.

Regarding the reversibility of all the experiments, Faradic reaction could be ignored.

\section{References}

[1] M. M. Mekonnen and A. Y. Hoekstra, "Four billion people facing severe water scarcity,"Sci. Adv., vol. 2, 2016.

[2] C. Zhang, D. He, J. Ma, W. Tang, and T. D. Waite, "Faradaic reactions in capacitive deionization (CDI) - problems and possibilities: a review," Water Res., vol. 128, no. 32, pp. 314-330, 2018.

[3] M. Shatat and S. B. Riffat, "Water desalination technologies utilizing conventional and renewable energy sources," Int. J. Low-Carbon Technol., vol. 9, no. 1, pp. 1-19, 2012.

[4] P. G. Youssef, R. K. Al-dadah, and S. M. Mahmoud, "Comparative analysis of desalination technologies,” Energy Procedia, vol. 61, pp. 2604-2607, 2014.

[5] K. S. Lee, Y. Cho, K. Y. Choo, S. Yang, M. H. Han, and D. K. Kim, "Membranespacer assembly for flow-electrode capacitive deionization," Appl. Surf. Sci., vol. 433, pp. 437-442, 2018.

[6] K. Dehghan, S. A. Mirbagheri, and and M. Alam, "A brief review on operation of flow-electrode capacitive deionization cells for water desalination," Desalin. Water Treat., vol. 223, pp. 34-53, 2021.

[7] D. D. Caudle, Electrochemical Demineralization of Water with Carbon Electrodes. 1966.

[8] Q. Yang, X. W. Li, and A. M. Fang, "Photovoltaic capacitive deionization regeneration method for liquid desiccant cooling system," Appl. Therm. Eng., vol. 117, pp. 204-212, 2017.

[9] X. Quan et al., "Capacitive deionization of $\mathrm{NaCl}$ solutions with ambient pressure dried carbon aerogel microsphere electrodes," RSC Adv., vol. 7, no. 57, pp. 35875-35882, 
2017.

[10] K. B. Hatzell and Y. Gogotsi, "Suspension electrodes for flow-assisted electrochemical systems," in Nanomaterials in Advanced Batteries and Supercapacitors, 2016, pp. $377-416$.

[11] P. Ratajczak, M. E. Suss, F. Kaasik, and F. Béguin, "Carbon electrodes for capacitive technologies," Energy Storage Mater., vol. 16, pp. 126-145, 2019.

[12] C. Zhang, D. He, J. Ma, W. Tang, and T. D. Waite, "Faradaic reactions in capacitive deionization ( CDI ) - problems and possibilities : A review," Water Res., vol. 128, no. 32, pp. 314-330, 2018.

[13] J. Lee, K. Jo, J. Lee, S. P. Hong, and and J. Y. Seonghwan Kim, "Rocking chair capacitive deionization for continuous brackish water desalination," ACS Sustain. Chem. Eng., vol. 6, no. 8, pp. 10815-10822, 2018.

[14] M. A. Ahmed and S. Tewari, "Capacitive deionization: Processes, materials and state of the technology," J. Electroanal. Chem., vol. 813, pp. 178-192, 2018.

[15] M. E. Suss et al., "Capacitive desalination with flow-through electrodes," Energy Environ. Sci., vol. 5, no. 11, pp. 9511-9519, 2012.

[16] P. Długołecki and A. Van Der Wal, "Energy recovery in membrane capacitive deionization," Environ. Sci. Technol., vol. 47, no. 9, pp. 4904-4910, 2013.

[17] Y. J. Kim, J. H. Kim, and J. H. Choi, "Selective removal of nitrate ions by controlling the applied current in membrane capacitive deionization (MCDI)," J. Memb. Sci., vol. 429, pp. 52-57, 2013.

[18] Y. J. Kim and J. H. Choi, "Improvement of desalination efficiency in capacitive deionization using a carbon electrode coated with an ion-exchange polymer," Water Res., vol. 44, no. 3, pp. 990-996, 2010.

[19] R. Zhao, P. M. Biesheuvel, And, and A. Wal, van der F., "Energy consumption and constant current operation in membrane capacitive deionization," Energy Environ. Sci., vol. 5, no. 11, pp. 9520-9527, 2012.

[20] X. Gao, A. Omosebi, J. Landon, and K. Liu, "Surface charge enhanced carbon electrodes for stable and efficient capacitive deionization using inverted adsorptiondesorption behavior," Energy Environ. Sci., vol. 8, no. 3, pp. 897-909, 2015.

[21] J. Lee, S. Kim, C. Kim, and J. Yoon, "Hybrid capacitive deionization to enhance the desalination performance of capacitive techniques," Energy Environ. Sci., vol. 7, no. 11, pp. 3683-3689, 2014.

[22] S. Porada, B. B. Sales, H. V. M. Hamelers, and P. M. Biesheuvel, "Water desalination with wires," J. Phys. Chem. Lett., vol. 3, no. 12, pp. 1613-1618, 2012.

[23] M. Pasta, C. D. Wessells, Y. Cui, and F. La Mantia, “A desalination battery," Nano Lett., vol. 12, no. 2, pp. 839-843, 2012.

[24] K. B. Hatzell et al., "Capacitive deionization concept based on suspension electrodes without ion exchange membranes," Electrochem. commun., vol. 43, pp. 18-21, 2014.

[25] M. E. Suss et al., "Water desalination via capacitive deionization: What is it and what can we expect from it?," Energy Environ. Sci., vol. 8, no. 8, pp. 2296-2319, 2015. 
[26] S. Jeon et al., "Desalination via a new membrane capacitive deionization process utilizing flow-electrodes," Energy Environ. Sci., vol. 6, no. 5, pp. 1471-1475, 2013.

[27] S. Yang et al., "Analysis of the desalting performance of flow-electrode capacitive deionization under short-circuited closed cycle operation," Desalination, vol. 424, pp. 110-121, 2017.

[28] A. Omosebi, X. Gao, J. Landon, and K. Liu, "Asymmetric electrode configuration for enhanced membrane capacitive deionization," ACS Appl. Mater. Interfaces, vol. 6, no. 15, pp. 12640-12649, 2014.

[29] P. Nativ, O. Lahav, and Y. Gendel, "Separation of divalent and monovalent ions using flow-electrode capacitive deionization with nanofiltration membranes," Desalination, vol. 425, pp. 123-129, 2018.

[30] M. Alam, S. A. Mirbagheri, and M. R. Ghaani, "Multi-parameter optimization of the capacitance of Carbon Xerogel catalyzed by $\mathrm{NaOH}$ for application in supercapacitors and capacitive deionization systems," Heliyon, vol. 5, no. 2, p. e01196, 2019.

[31] M. Alam, S. A. Sadrnejad, and M. R. Ghaani, "Performance evaluation of optimized Carbon Xerogel electrode in desalination through flow-electrode capacitive deionization: Capacitance optimization by response surface methodology," Desalin. Water Treat., vol. 145, pp. 57-69, 2019.

[32] P. Liang et al., "Optimized desalination performance of high voltage flow-electrode capacitive deionization by adding carbon black in flow-electrode," Desalination, vol. 420, pp. 63-69, 2017.

[33] P. Nativ, Y. Badash, and Y. Gendel, "New insights into the mechanism of flowelectrode capacitive deionization," Electrochem. commun., vol. 76, pp. 24-28, 2017.

[34] C. J. Linnartz, A. Rommerskirchen, M. Wessling, and Y. Gendel, "Flow-Electrode Capacitive Deionization for Double Displacement Reactions," ACS Sustain. Chem. Eng., vol. 5, no. 5, pp. 3906-3912, 2017.

[35] D. Moreno and M. Hatzell, "The influence of feed-electrode concentration differences in flow-electrode systems for capacitive deionization," Ind. Eng. Chem. Res., vol. 57, no. 26, pp. 8802-8809, 2018.

[36] J. Ma, C. He, D. He, C. Zhang, and T. D. Waite, "Analysis of capacitive and electrodialytic contributions to water desalination by flow- electrode CDI," Water Res., vol. 144, pp. 296-303, 2018.

[37] C. He, J. Ma, C. Zhang, J. Song, and T. D. Waite, "Short-circuited Closed-cycle Operation of Flow- electrode CDI for Brackish Water Softening," Environ. Sci. Technol., vol. 52, no. 16, pp. 9350-9360, 2018.

[38] X. Xu, M. Wang, Y. Liu, T. Lu, and L. Pan, "Ultrahigh desalinization performance of asymmetric flow-electrode capacitive deionization device with an improved operation voltage of 1.8 v," ACS Sustain. Chem. Eng., vol. 5, no. 1, pp. 189-195, 2017.

[39] Z. Sun et al., "Capacitive deionization of chloride ions by activated carbon using a three-dimensional electrode reactor," Sep. Purif. Technol., vol. 191, pp. 424-432, 2018.

[40] K. Luo et al., "Desalination behavior and performance of flow-electrode capacitive deionization under various operational modes," Chem. Eng. J., vol. 389, pp. 1-10, 
2020.

[41] Z. Chen, H. Zhang, C. Wu, Y. Wang, and W. Li, "A study of electrosorption selectivity of anions by activated carbon electrodes in capacitive deionization," Desalination, vol. 369, pp. 46-50, 2015.

[42] S. Yang et al., "Stack design and operation for scaling up the capacity of flowelectrode capacitive deionization technology," ACS Sustain. Chem. Eng., vol. 4, no. 8, pp. 4174-4180, 2016.

[43] C. H. Hou, C. Y. Huang, and C. Y. Hu, "Application of capacitive deionization technology to the removal of sodium chloride from aqueous solutions," Int. J. Environ. Sci. Technol., vol. 10, no. 4, pp. 753-760, 2013.

[44] T. Y. Ying, K. L. Yang, S. Yiacoumi, and C. Tsouris, "Electrosorption of ions from aqueous solutions by nanostructured carbon aerogel," J. Colloid Interface Sci., vol. 250, no. 1, pp. 18-27, 2002.

[45] K. L. Yang, S. Yiacoumi, and C. Tsouris, "Electrosorption capacitance of nanostructured carbon aerogel obtained by cyclic voltammetry," J. Electroanal. Chem., vol. 540, pp. 159-167, 2003.

[46] C. H. Hou, C. Liang, S. Yiacoumi, S. Dai, and C. Tsouris, "Electrosorption capacitance of nanostructured carbon-based materials," J. Colloid Interface Sci., vol. 302, no. 1, pp. 54-61, 2006. 